\title{
SEX, DRUGS AND
}

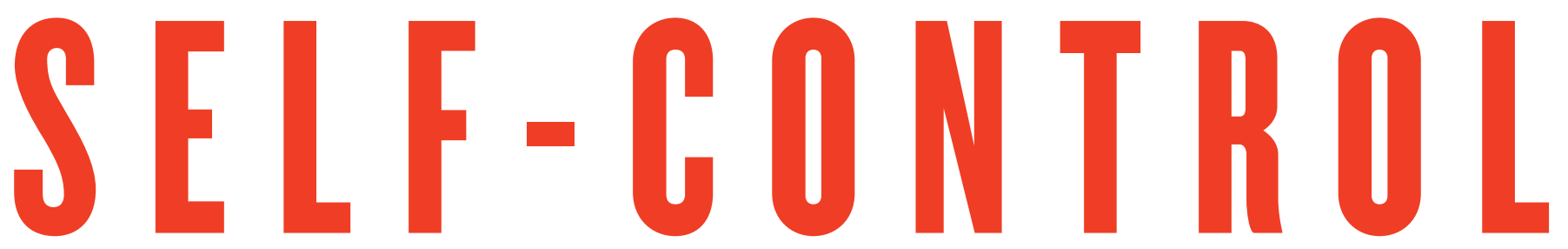

\section{It's not just about rebellion. Neuroscience is revealing adolescents' rich and nuanced relationship with risky behaviour.}

BY KERRI SMITH

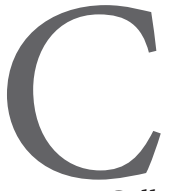

ole Skinner was hanging from a wall above an abandoned quarry when he heard a car pull up. He and his friends bolted, racing along a narrow path on the quarry's edge and hopping over a barbed-wire fence to exit the grounds.

The chase is part of the fun for Skinner and his friend Alex McCallum-Toppin, both 15 and pupils at a school in Faringdon, UK. The two say that they seek out places such as construction sites and disused buildings - not to get into trouble, but to explore. There are also bragging rights to be earned. "It's just something you can say: 'Yeah, I've been in an abandoned quarry", says McCallum-Toppin. "You can talk about it with your friends."

Science has often looked at risk-taking among adolescents as a monolithic problem for parents and the public to manage or endure. When Eva Telzer, a neuroscientist at the University of North Carolina in Chapel Hill, asks family, friends, undergraduates or researchers in related fields about their perception of teenagers, "there's almost never anything positive", she says. "It's a pervasive stereotype." But how Alex and Cole dabble with risk - considering its social value alongside other pros and cons - is in keeping with a more complex picture emerging from neuroscience. Adolescent behaviour goes beyond impetuous rebellion or uncontrollable hormones, says

Adriana Galván, a neuroscientist at the University of California, Los Angeles. "How we define risk-taking is going through a shift."

Adolescents do take more risks than adults, and the consequences can include injury, death, run-ins with the law and even long-term health problems. But lab studies in the past decade have revealed layers of nuance in how young people assess risks. In some situations, teenagers can be more risk-averse than their older peers. And they navigate a broader range of risks than has typically been considered in the lab, including social risks and positive risks - such as trying out for a sports team. These types of behaviour seem to have different effects on the brain.

How adolescents interact with risk is important. Work on the neural underpinnings of risky behaviour can inform guidelines and laws for teens who drive, for example, or the punishments they receive for violent crimes. Understanding how the teenage brain evaluates risk could even reveal predictors of mental-health conditions such as schizophrenia and depression, which often emerge in adolescence.

In more ways than one, there is a lot going on in a teenager's head. "In fact, it's just beautiful," says B. J. Casey, a neuroscientist at Yale University in New Haven, Connecticut. "It's amazing that it unfolds correctly most of the time."

\section{REBEL WITH A CAUSE}

Adolescence is a perilous period. The death rate among 15- to 19-yearolds worldwide is about 35\% higher than that among 10- to 14-year-olds. And risky behaviours are linked to many of the major threats to life during this time (see 'Risking life and limb'). Road injuries are the biggest cause of death for adolescents globally. Self-harm and other forms of violence also rank highly. Plus, some practices that can lead to poor health in adulthood - such as use of tobacco or alcohol, or sedentary lifestyles - often stem from poor choices made in the teenage years. So, risky behaviour has been a preoccupation for scientists.

"Risk-taking has driven a lot of the early work" on the teenage brain, says Ronald Dahl, who studies adolescent brain development at the University of California, Berkeley. "It was a route to successful funding, so it was emphasized."

Early theories focused on a perceived imbalance in the developing brain. Areas linked with impulsivity and heightened sensitivity to reward, especially in the social realm, get an early boost in activity, whereas those governing cognitive processes such as working memory develop smoothly throughout adolescence.

Neuroscientists likened the emerging picture of the teenage brain to that of a car with a revving accelerator and faulty brakes. This fit the developmental data, but not the fact that many teenagers show no proclivity for risk-taking, says Ted Satterthwaite, a psychiatrist and neuroimaging researcher at the University of Pennsylvania in Philadelphia. A 2016 


\section{RISKING LIFE AND LIMB}

In 2015, an estimated 1.2 million people aged 10-19 died. Many of the leading causes of death, particularly for older adolescents and males, are related to risky behaviours.

$10-14 \square 15-19$

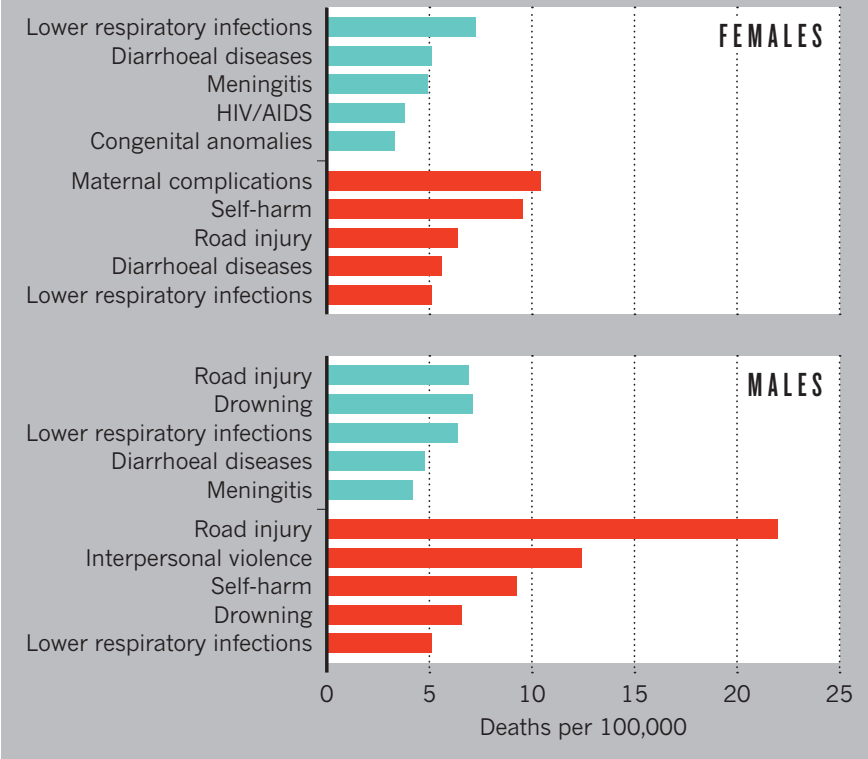

of dopamine receptors, has been linked to the greater sensitivity that teenagers feel to rewards for positive as well as perilous behaviours.

Telzer's studies ${ }^{7}$ suggest that teenagers who show heightened ventral striatum activity when making decisions that help others, such as donating money, take fewer risks in the long term and have a lower risk of depression as adults. "There's very much a yin and yang to this," says Dahl.

There are limitations to these lab-based studies; it's hard to reproduce the social whirl of teenage life in a scanner, says Galván. "How do we emulate what's going on on Saturday night in a cold lab on a Tuesday afternoon?" she asks. The studies are more likely to capture a teenager's inclination for risk than the likelihood of real-world risk-taking, Galván says.

The other problem is that the average teenager in a study is only moderately likely to take risks. "Most of what we know about adolescent risk-taking is actually derived from relatively normative samples," says Telzer, "not adolescents engaging in high levels of risk-taking behaviour." Dangerous risk-taking could be confined to a small proportion of teenagers, and there is evidence that they process risk very differently from their peers.

\section{HIGH-RISK RESEARCH}

Telzer ran an as-yet-unpublished study in 2015 with adolescents who had been expelled from a school for serious offences. Her team asked them to lie in a scanner and push a button when they saw letters on a screen, but not if the screen displayed an 'X'. Images with social significance - positive pictures such as teenagers laughing or playing games on a beach, and negative ones including a group ganging up on someone - also appeared on screen. Most teenagers were worse at the button-pressing task when the images were positive; their cognitive control was overridden by the rewarding picture. Activity in the ventral striatum went up in tandem. But among the expelled or suspended students, it was the aversive pictures that impaired performance. The teenagers' lack of control, Telzer says, seems to come from a different type of reaction to social stimuli.

Scientists have assumed that the young people who take the most risks show an extreme version of the standard teenager brain profile, says Telzer. But perhaps, she says, they are "a very different type of adolescent".

Research on risk-taking has begun to inform the US justice system. Authorities are taking into account, for example, the factors that might impair a teenager's self-control. Studies show ${ }^{8}$ that in emotionally neutral situations, young adults perform cognitive tasks just as well as older adults But when the situation is emotionally charged, their performance drops off. This and other work could suggest that crimes in emotionally 'cold' situations should be considered differently from those in which 'hot', or emotionally led, decision-making takes over. Similar work could provide ways of pinpointing teenagers at high risk of doing something dangerous.

Steinberg testified in five court cases last year concerning criminal sentences for adolescents. After hearing his evidence on how decisionmaking in teens is influenced by emotion, a Kentucky court last year decided to raise to 21 the age at which individuals could be given the death penalty. And the evidence has also been enlisted in arguments against mandatory life sentences without parole for offenders under 21 .

Scientists are excited about the possibility that this body of developmental research can inform policy. But some, such as Satterthwaite and Galván, point out some challenges in using fMRI data in court for individual cases. The data from neuroimaging studies are usually averaged out across participants, so drawing conclusions about any one brain is itself risky. "Honestly, I don't think neuroimaging should be used," Satterthwaite says. "It's too noisy."

The data are also too noisy for diagnosis, but Satterthwaite is tantalized by evidence that the young brain's response to risk might reveal early symptoms of depression or anxiety. He would like to see research get to the point at which it could guide clinical treatment. "The idea that you can come see me with a life-threatening condition, and leave with no diagnostic test, no imaging, no lab test - that's medieval," he says.

The broader research on adolescent risk is already helping to minimize dangerous behaviour in daily life. For instance, adolescents who don't get enough sleep are more prone to a host of risk-taking behaviours, such as smoking and sexual activity. Dozens of studies ${ }^{9}$ on the effects of increasing sleep by delaying school start times - a move endorsed by bodies such as the US Centers for Disease Control and Prevention and the American Academy of Pediatrics - suggest that many of these problems, including risky behaviours, improve when schools start later. The academy recommends a start time of 8:30 or later; hundreds of schools in the United States have delayed their first bell, but in 2014 the median start time for middle school was still 8:00.

Steinberg has advocated limiting exposure to risk in the first place, for example by raising the minimum age for buying tobacco to 21 or prohibiting alcohol sales within 300 metres of schools. This is likely to work better than approaches based on informing students about risks, he says. Other policies aim to take away the opportunity for dangerous behaviour. Graduated-licensing schemes in Australia, New Zealand, Northern Ireland and the United States compel young drivers to build up experience before they are allowed to drive with only teenage passengers. Such programmes have been shown to reduce casualties among young drivers.

But a little bit of risk is a good thing, says Casey. "I wouldn't say that we want people to stop taking risks", she says. "A lot of it is allowing them to be adults in safe situations."

Adolescents have a lot to learn in their transition to relative independence - and nobody said it was easy. "I can't think of a more challenging period of development," says Casey. "Every time I give a talk, I ask people to raise their hand if they want to go through adolescence again. And no one does." -

\section{Kerri Smith is a News Feature editor at Nature, based in London.}

1. Johnston, L. D. et al. Monitoring the Future: National Survey Results on Drug Use, 1975-2016 - 2016 Overview, Key Findings on Adolescent Drug Use (Univ. Michigan, 2017); available at http://go.nature.com/2ngttbt

2. Chein, J., Albert, D., O'Brien, L., Uckert, K. \& Steinberg, L. Dev. Sci. 14, F1-F10 (2011).

3. Telzer, E. H., Ichien, N. T. \& Qu, Y. Soc. Cogn. Affect. Neurosci. 10, 1383-1391 (2015).

4. Peake, S. J., Dishion, T. J., Stormshak, E. A., Moore, W. E. \& Pfeifer, J. H. Neuroimage 82, 23-34 (2013)

5. Telzer, E. H., Miernicki, M. E. \& Rudolph, K. D. Dev. Psychopathol. 30, 13-26 (2018)

6. van Hoorn, J. et al. Res. Adolescence 26, 90-100 (2016).

7. Telzer, E. H., Fuligni, A. J., Lieverman, M. D. \& Galván, A. Proc. Natl Acad. Sci. USA 111, 6600-6605 (2014).

8. Cohen, A. O. et al. Psychol. Sci. 27, 549-562 (2016).

9. Wheaton, A. G., Chapman, D. P. \& Croft, J. B. J. Sch. Health 86, 363-381 (2016) 